\title{
THE ROLE OF ELITES IN THE DIFFUSION OF SOCIAL NORMS OF HUMANITARIANISM
}

\author{
Khadijeh Salimi \\ Graduate Program in International Studies \\ Old Dominion University \\ 7045 Batten Arts \& Letters \\ Norfolk, VA 23529 USA
}

\author{
Erika Frydenlund \\ Jose J. Padilla \\ Virginia Modeling, Analysis \& Simulation Center \\ Old Dominion University \\ 1030 University Boulevard \\ Suffolk, VA 23435 USA
}

\author{
Hanne Haaland \\ Hege Wallevik \\ Department of Global Development \& Planning \\ University of Agder \\ N-4604 Kristiansand \\ NORWAY
}

\begin{abstract}
Certain social norms evolve without punishment as conventions that do not adversely affect society. In this paper, we depart from the notion that humanitarianism is one such social norm, where peer pressure may be the only type of punishment that encourages individuals to conform. Using an agent-based modeling approach, we examine the role that networked elites have in diffusing a non-punishment-enforced norm through an artificial society. The model considers norm advocates who promote a norm of humanitarianism, elites who have wide networks to spread the new norm, and general individuals who evaluate the norm pushed from elites and adopted by their peers. The study finds that, regardless of starting parameter values, the population converges into two groups: norm adopters and those who oppose the norm.
\end{abstract}

Keywords: agent-based modeling, norm diffusion, humanitarianism, elites.

\section{INTRODUCTION}

Not very far from the southern border of the United States, over one million Venezuelans have fled their country's economic collapse into neighboring countries and other host countries throughout the world (Bahar 2018, UNHCR 2018). Likewise, over one million migrants fleeing an array of global crises have arrived at Europe's borders since 2015 (UNHCR 2017). The vast humanitarian need is overwhelming many of the border and host communities (Daniels 2018, Cosse 2017). Even in our own communities, social problems confront us daily, such as hunger, homelessness, and poverty. How ready is any one person to help another in need? How far would an ordinary person go to alleviate another's suffering or improve their life conditions or opportunities? For some, like many of the individuals who gave up their careers and lives to become full-time volunteers to help refugees in Europe (Haaland and Wallevik 2014), the potential for humanitarianism is very great. Some may contribute financially from a distance, while others feel completely unmoved to change any of their life patterns or practices to contribute to humanitarian response. We define 'humanitarianism' here to be an individual's potential to help another who is socially, economically, or politically precarious. This varies from small financial contributions to those who change the course of their lives to become volunteers for humanity. We depart from the premise that individuals have a propensity to be convinced of some level of humanitarianism. Perhaps this is through a personal interaction where someone on vacation in Medellin, Colombia observed Venezuelan migrants sleeping in 
the street and felt called to action. Or, consider someone who spoke with that tourist to Medellin and felt compelled to start donating funds or goods to help Venezuelans fleeing economic insecurity. In this study, we also focus on 'elites' as a means to promote humanitarian values through their social networks. The objective of this research is to understand how humanitarian norms that lack associated punishments for non-compliance diffuse across society. We consider three types of actors: ordinary people, elites with social influence, and advocates who zealously promote humanitarian norms to elites. These actors form a system in which individuals adopt varying levels of humanitarian values through repeated interactions with others.

\section{HOW ARE HUMANITARIAN NORMS DIFFERENT?}

Before talking about the diffusion of norms, we must first define what we mean by 'norms,' specifically 'humanitarian norms.' Scholars from various disciplines have tried to define and understand norms, but it is not a simple task. Broadly, many scholars agree that a 'norm' is a standard of appropriate behavior for people sharing a particular identity (Katzenstein 1996, Finnemore 1996, Klotz 1995). Elster (1989) contends that social sanctions make obedience of a norm into a rational decision/action; thus, in order for a norm to take hold, there must be some kind of sanction, punishment, or cost of disobedience. Villatoro (2010) took this idea further by classifying norms according to the social sanction. He defines an 'essential norm' as one that punishes disobedience, while 'convention' refers to a norm with no threat of punishment for disobedience. An essential norm is like the traffic violation one might receive while running a red light for the sake of one's own interest (being late) and challenging the public interest (obeying traffic rules). In contrast to essential norms, conventions are those norms that emerge naturally in society and cause no conflict of interest among its members, such as shaking hands when greeting in Western cultures. While much work is devoted to the study of essential norms, we focus here on humanitarian norms as conventions. In this case, individuals ascribe to a humanitarian value system not through punishment (overt or passive social punishments or sanctions), but simply by interacting with others who have the potential to change each person's mind. Here, we present a case of norm diffusion where there is no punishment for adopting the norm of humanitarianism, and individuals are influenced by peers as well as elite actors who represent those with significant social status, such as politicians, celebrities, and other influential public figures.

\subsection{Norm Diffusion in Simulation}

Not only has norm diffusion been a subject of interest in a variety of disciplines, it has also been the center of many different modeling paradigms, from Game Theory to social network analysis to agent-based modeling (ABM). From a modeling perspective, scholars are interested in the study of norm diffusion and adaptation based on individuals' motivations. As a mechanism to motivate norm adoption, scholars look at punishment (Axelrod 1986, Lopez 2003, Lopez, Luck, and d'Inverno 2002, Flentge, Polani, and Uthmann 2001, Savarimuthu et al. 2010), imitation and conformity (Epstein 2001, Conte and Paolucci 2001), compliance (Young 1996, Young 1993, Epstein 2001) and memes (Gatherer 2002, Flentge, Polani, and Uthmann 2001). The notion of compliance through threat of punishment suggests that individuals only accept norms because they fear punishment, for instance having to pay a fine for violating traffic regulations. Simulationists have captured these mechanisms by looking specifically at how norms interact with behaviors and are influenced by implicit and explicit punishment (Dignum and Dignum 2009).

Since we are looking specifically at humanitarian norms, we are not as interested in punishment and compliance to motivate adoption; rather, we are interested in individuals feeling some peer pressure to imitate and conform both to highly networked individuals and others who are spatially close to them. Of course, as human beings our actions and thoughts are relatively bound to what other people are saying or thinking about us. This notion follows from the idea of peer pressure, where an individual observes they are in the minority and adopts the norm, succumbing to the pressure of those around them (Epstein 2001, Young 1993, Young 1996). Norm adoption through imitation is mainly based on cognitive science (Conte and Paolucci 2001). Simulation often captures the notion of adaptation by endowing agents with the ability 
to learn, often through cooperative games, and attempts to reach an equilibrium or maximize the utility of the collective of individuals (Sen and Airiau 2007, Powers and Shoham 2004, Wolpert and Tumer 2002). Others have used simulation to demonstrate how norms are inversely related to cognitive effort (Axelrod 1986); in other words, we adopt norms because others do and it makes it easier to not think about. We draw on this idea of norm adoption without punishment or sanctions and introduce a number of different agent types to explore how norms diffuse before they become institutionalized through penalties.

This model relies on theories from International Relations and Constructivist theoretical frameworks to look at how norms are adopted at the individual level to manifest macro-level instances of adoption. The major drivers of norm adoption are peer pressure and conformity, with no instantiation of punishment. Agents in the model are pursuing the adoption of humanitarian norms, namely the propensity to start or join humanitarian organizations in the various typologies that comprise those types of people in the field (Haaland and Wallevik 2014). In our model, agents are able to assess the norm adoption of those who are near them as well as individuals they meet one-on-one to determine whether to adopt the norm.

Like many other norm diffusion theories and models, we borrow from Finnemore and Sikkink's (1998) theory of norm diffusion. They describe (at the state level) a norm life cycle that proceeds through three steps: emergence, cascade, and internalization. As a norm passes the tipping point into the cascade phase, the adoption becomes more rapid, followed by an internalization stage where norms become entrenched and mostly followed without much thought about counter-norms (Axelrod 1986). While Finnemore and Sikkink described the norm life cycle as a linear process, Moskovko (2012) visualizes this as a tipping point. The adapted visualization helps to center our research interest, which is specifically on the emergence to cascade stages. As mentioned above, the internalization (and institutionalization) of norms is outside the scope of the current project.

\subsection{The Norm Lifecycle}

The first step of a norm's life cycle is emergence. At this stage, individuals or groups begin promoting and promulgating a norm. In norm diffusion theory, these actors are generally called 'norm entrepreneurs' or 'norm promoters' (Finnemore and Sikkink 1998) who try to 'sell' a new idea. Since our model is about humanitarianism, we call these actors 'advocates' who fervently believe in a particular cause and whose enthusiasm will never change about that cause. Advocates, based on the norm literature, are individuals who really believe in the norm based on their childhood, religious, ethical, or moral values (March and Olsen 1998). In other words, they have already internalized that norm as an appropriate way of behaving, and try to convince others to behave in this way, too. Finnemore and Sikkink (1998) see norm promoters/advocates as crucial for the norm emergence stage because they establish a cognitive framing of appropriate behavior that others later adopt.

Advocates are not always socially positioned to be effective norm promoters on their own. For this reason, they rely on 'elites' (Finnemore and Sikkink 1998) - individuals in a society who have large networks and strong influence over others such as celebrities and politicians. By convincing elites to adopt norms, advocates increase their ability to reach a wider public audience. It should be noted that advocates promote a norm based on a logic of appropriateness, while elites advertise a norm based on the logic of consequences (March and Olsen 1998). In other words, advocates are often not assessing the utilities or benefits of the norm and will never change their mind about that norm; they are like zealots. Elites, on the other hand, assess the utilities and benefits of norm adoption relative to their level of social power. Iglič and Rus (2000) suggest that less powerful, 'new' elites may be targets of advocates because they see the new norm as a potential tool to maximize their utility and balance power against more powerful, 'old' elites.

The tipping point in the norm life cycle is reached when the balance of power between opponent and proponent of the new norm has shifted. At that point, the new norm will become the dominant norm (Gilardi 2010). When the norm's life cycle reaches the tipping point, it means a considerable percentage of the 
population supports that norm. After this point, the spread of the norm will reach a higher speed compared to the previous step, and many people from different groups of society may adopt the norm. Based on our earlier findings (Salimi et al. 2018), norm cascading for humanitarian norms may be different from other norms because degradation of humanitarian values has a diverse and exponential relation to the percent of advocates and therefore is a limiting factor in this process of cascading. This denotes a key difference in norms that have associated punishments, which would prevent individuals from losing interest in a norm over time and delaying the cascade process of norm adoption.

During the cascade phase, elites must socialize a norm to persuade others to adopt. Since individuals' motivation to adopt a new norm is based on the logic of consequences, it is impossible for elites to persuade others who have no desire to be a part of that social group (Flockhart 2010). Again, this is an important distinction between norms that are adopted through punishment mechanisms. In fact, peer pressure may be regarded as a form a social punishment by which certain norms are socialized to others and individuals find that socially the benefits of adoption outweigh the costs (Finnemore and Sikkink 1998).

The final stage is internalization. At this point, people take the norm for granted and there is no more debate over it. Practicing or enacting the norm becomes a legitimate, accepted behavior (Wendt 1999), or even a way of seeking happiness or fulfillment, what Lebow (2008) calls 'reason-based action'.

\section{AN AGENT-BASED APPROACH FOR THE THEORY OF NORM DIFFUSION}

Finnemore and Sikkink (1998) propose one of the most dominant theories of norm diffusion from a Constructivist perspective. Their theory is a top-down, or 'legalistic' view (Villatoro 2010). In this view, a central authority regulates the norm. Individuals have little freedom to create the norm and regulators sanction those who do not obey the norm. However, our approach in this paper is from bottom-up or interactionist perspective in which a norm is created and regulated by the individuals (Flockhart 2006). In the interactionist view, emergence of norms can happen without any enforcement because individuals share the same values and goals, or perceive themselves as a part of a group. Agents in the model encounter one another and, using an algorithm to determine how persuasive someone else's stance on the norm of humanitarianism is, they adjust their own viewpoint slightly (for or against) along a continuous scale (Jager and Amblard 2005). Each assesses this value based on their individual, heterogeneous threshold for adopting the norm. Each agent begins with its own starting level of "humanitarianism," threshold for adoption, and thresholds for listening and adjusting to other agents' opinions about humanitarianism. For this type of norm, the extent of punishment for norm violation may be social stigma or abandonment of disobedient individuals. In this sense, we capture the essence of a social punishment as 'peer pressure.' Borrowing from Finnemore and Sikkink (1998), we define three types of agents in our model. Because the motivation and means of adoption are different between advocates and elites (one-way versus two-way respectively), we consider these actors two separate types of agents, with the third type being general individuals. The following section defines the three agent types in the model.

\subsection{Humanitarian Advocates}

Humanitarian advocates are those who work most enthusiastically in the initial phase of the norm lifecycle to promote the norm to elites and other individuals. These agents do not need to be convinced of the value of humanitarianism as they have already internalized the humanitarian norm. The reason they are so convinced of this norm varies from childhood experience, personal encounter, to critiques of the established aid environment (Haaland and Wallevik 2014). In the model, advocates operate much like the general population in that they try to convince others they encounter one-on-one to adopt a norm. Different from general agents, however, advocates never adjust their level of enthusiasm for the norm and they specifically seek out elites who have not adopted the norm to convince. 


\subsection{Elites}

Elites in this model are more than just those who attempt to convince political leaders to adopt norms (Finnemore and Sikkink 1998). They also include a spectrum of famous, influential people such as actors, athletes, religious figures, and other types of mavens who have large social networks through which to disperse information and convince others of the merits of particular norms. This group plays a crucial role in encouraging the general population to adopt the emerging norm. Elites are more influential than ordinary people due to their wide networks and the phenomenon of their followers mimicking their behavior because they are considered successful by some material or status measures (Wendt 1999). This act of imitation strongly influences the transition of a new norm (Richerson and Boyd 2005, Hurley and Chater 2005), and can even form the basis for social regulation through conformity, which tips the cost/benefit calculation for others in the general population for norm adoption (Elsenbroich and Gilbert 2013). On the other hand, religious elites can also use moral and religious pressure to influence people to donate or help people in need (Lehmann 2005). Boyer (2002) explains how religious elites' invocation of people's "inference system" play roles in everyday interactions and can regulate their feelings of guiltiness and fairness.

As mentioned above, elites' actions are based on the logic of consequences in which they seek to maximize their benefits. Thus, in contrast to advocates, elites may change their mind during the process of norm adoption based on their situation and interests. Additionally, elites adopt norms mostly through interaction with advocates, with very little weight placed on the adoption preferences of ordinary individuals they encounter in the simulation environment. Once the elite updates their preference for norm adoption, they push this value out to their social networks to influence the norm adoption (for or against) of their followers.

\subsection{General Population}

The most common agent in the model represents the general population. These individuals also act based on the logic of consequences and seek to maximize their utility. Unlike the elites, they do not (currently) possess social networks and instead spread norms through spatial proximity. Unlike advocates and elites, they consider interactions with all agent types to change their opinion both for and against adopting norms. While there are no sanctions in the model, general individuals consider the aspect of peer pressure. This opinion varies along a continuous scale so, like the elites, individuals can shift from norm adoption to nonadoption after different encounters with others. This idea of conformity is observed in a wide range of disciplines including political science (Waltz 2010) and economics (Young 2006). In the model, individual agents attempt to match the majority within a small vision radius to maximize their utility (Epstein 2001, Young 2006, Axelrod 1986). In addition to considering one-on-one interactions with other agents, general individuals look to those around them, assess how many are norm adopters, and, if that number exceeds the level of their comfort with non-conformity, they adopting the norm.

Conformity with the elites with whom they are networked also affects the general population's opinions about a norm. This is not universally weighted; each individual agent has a unique weight that they place on the information conveyed through their networked elites. Some agents weight the opinions of the elites they follow very heavily, while others do not place much emphasis on their elites' influence.

\section{SIMULATION OUTCOME}

The purpose of this model is to understand the impact of elites in the spread of norms as an extension of a previous model (Salimi et al. 2018). This model is not yet at a stage where we are prepared to verify and validate the model, so we instead performed diagnostics on the model using the ANTS algorithms to look for anomalies across the parameter space (Miller 1998). The diagnostics did not indicate problems with the current prototype model that produce erratic results or unexplained outcomes. Future iterations of the model will look to more robust methods of verification and validation. The current model, founded predominantly on norm diffusion theory, is designed to test assumptions of norm diffusion theories in an environment 
where peer pressure is the only mechanism for punishment-based enforcement of norm adoption. Table 1 describes the parameters of the model and the possible values.

Table 1: Variable Descriptions and ranges.

\begin{tabular}{|c|c|c|}
\hline & Description & Range \\
\hline \multicolumn{3}{|c|}{ Elite-centric variables } \\
\hline percent-elites & Percentage of population who are elites (influencers) & {$[0,2]$} \\
\hline $\begin{array}{l}\text { advocate-weight- } \\
\text { e }\end{array}$ & Weight advocate exerts on the elite agent's humanitarianism values & {$[0,1]$} \\
\hline peer-weight-e & Weight placed on interactions with other elite agents & {$[0,1]$} \\
\hline network-size & Randomized size of network of 'followers' of elites & {$[0,500]$} \\
\hline \multicolumn{3}{|c|}{ General population variables } \\
\hline advocate-weight-g & Weight the advocate exerts on general agents & {$[0,1]$} \\
\hline elite-weight & Weight given to a networked elite's norm adoption & {$[0,1]$} \\
\hline general-weight & Weight given to a one-on-one interaction with a general agent & {$[0,1]$} \\
\hline peer_weight_g & $\begin{array}{l}\text { Weight given to average humanitarian values of a group of nearby } \\
\text { agents }\end{array}$ & {$[0,1]$} \\
\hline \multicolumn{3}{|c|}{ Advocate-centric variables } \\
\hline percent-advocates & $\begin{array}{l}\text { What percentage of agent population are advocates who promote } \\
\text { a norm }\end{array}$ & {$[0,1]$} \\
\hline advocate-zeal & $\begin{array}{l}\text { Homogeneous value given to advocate agents' humanitarianism } \\
\text { values }\end{array}$ & {$[0,1]$} \\
\hline \multicolumn{3}{|l|}{ Global variables } \\
\hline degrade-percent & $\begin{array}{l}\text { Amount per time step that an agent degrades its humanitarianism } \\
\text { values, to represent donor/compassion fatigue }\end{array}$ & {$[0,100]$} \\
\hline mu-activist-state & Mean humanitarianism value of all general agents (heterogeneous) & {$[0,1]$} \\
\hline $\begin{array}{l}\text { mu-activist- } \\
\text { threshold }\end{array}$ & $\begin{array}{l}\text { Mean threshold value of all general agents beyond which they } \\
\text { become active humanitarian actors (heterogeneous) }\end{array}$ & {$[0,1]$} \\
\hline Population & Total population of agents & {$[500,1000]$} \\
\hline
\end{tabular}

In each time step, agents (all types) move around the environment. If they encounter another agent, they will interact one-on-one and general agents may each adjust their opinion about humanitarianism based on their own value thresholds and the partner-agent's opinion. The general agents will also take into consideration how many other nearby agents have adopted the humanitarian norm and update their opinion using a heterogeneous weighting factor based on the average of opinions around them; if the percentage of adopters nearby is above their individual threshold for conformity, they will conform regardless of whether 
their opinion aligned with humanitarianism. Advocates interact one-on-one with general agents, but primarily seek out elite non-adopters who they try to convince to adopt the norm. As elites update their opinion on humanitarianism based mainly on interactions with advocates, they push this opinion to general agents in their network, who then update their opinion based on the heterogeneous weight that they place on elite interactions.

\subsection{Experimental Design}

There are not currently any standardized ways to design simulation experiments for large computer simulations. Since we are working with an ABM that includes three different types of agents, each with its own set of parameters, the design space includes 14 variables and complicates our choices of experimental designs. The simulation runs followed a Latin Hypercube design with 100 parameter combinations or design points, and each point was repeated 5 times (see Table 1 for the parameter value ranges). The values recorded for statistical analysis consist of the final percentage of general norm adopters and elite norm adopters at the end of each simulation run. Each simulation was run for 200-time steps, the point by which nearly all simulations converge to a stable number of norm adopters which is a point for later discussion.

\subsection{Results}

Using the percent of adopters for general agents and elite agents as dependent variables, we constructed two Ordinary Least Squares (OLS) regression models to evaluate the effect of the parameters on the outcome of norm adoption. After we constructed the full model, we ran diagnostics on the model to determine whether the assumptions of OLS are met. There are no indications of violations of normality, homoscedasticity, linearity, collinearity, or independence, and no major outliers in the data. Finally, we performed a backwards stepwise regression to generate the "reduced" models in Table 2.

Starting with the models that uses percentage of elites as the dependent variable, we find that almost nothing affects the number of elites who end up adopting the norm in the model. Only the activist threshold, which the elite also uses to assess how to change its opinion relative to the advocate agent's opinion, is statistically significant indicating that an increase in the threshold decreases the percentage of elites who become norm adopters. This is expected since the higher the threshold, the more averse an agent is to new ideas. The fact that no other factors are statistically significant is not too surprising since elites only take input from advocates. Advocates in some cases far outnumber the elites, and have very strong opinions about humanitarianism — so strong that the elite may find the advocate's zeal off-putting and decide not to adopt.

The threshold value has a similar impact on the percentage of general agents who end up adopting the norm. Interestingly, in both models, the average starting opinion of elites and general agents has no statistically significant effect on the outcome of either agent type adopting the norm. General agents are greatly impacted by the percentage of degradation that occurs to their opinion about humanitarianism at each time step. This feature of the model was included to counter the idea of punishment for non-adopters, and to capture the donor/compassion fatigue observed by aid organizations that attempt to generate compassion for humanitarian causes. For each percentage that opinions about humanitarianism are allowed to degrade, we see a nearly one percent decrease in the number of norm adopters at the end of the simulation run.

The most influential factor affecting norm adoption by general agents is the average amount of weight they place on peer groups. Note that this is heterogeneous for each agent, but the average value of the distribution of weights is set as a simulation parameter; additionally, this is the weight placed on group assessments rather than one-on-one. As other models have suggested (Epstein 2001, Young 1996), peer pressure becomes a significant means of spreading norms through the population, while the weight placed on oneon-one interactions has no statistical effect on the outcome of norm adopters. The percentage of elites also has a significant impact on the number of general agents who eventually adopt the norm, as does the weight that individuals place on the opinion of elites in terms of influencing their own opinions about humanitarianism. 
Table 2: OLS regression output for statistical models of simulation runs.

\begin{tabular}{|c|c|c|c|c|}
\hline VARIABLES & $\begin{array}{c}(1) \\
\text { Elite-F }\end{array}$ & $\begin{array}{c}(2) \\
\text { Elite-R }\end{array}$ & $\begin{array}{c}(3) \\
\text { General-F }\end{array}$ & $\begin{array}{c}\text { (4) } \\
\text { General-R }\end{array}$ \\
\hline percent_elites & $\begin{array}{c}0.429 \\
(1.236)\end{array}$ & & $\begin{array}{c}13.651 * * * \\
(2.273)\end{array}$ & $\begin{array}{c}13.689 * * * \\
(2.197)\end{array}$ \\
\hline advocate_weight_e & $\begin{array}{l}1.561 \\
(2.378)\end{array}$ & & $\begin{array}{l}-3.282 \\
(4.372)\end{array}$ & \\
\hline peer_weight_e & $\begin{array}{l}-0.924 \\
(2.547)\end{array}$ & & $\begin{array}{l}-5.642 \\
(4.684)\end{array}$ & \\
\hline network_size & $\begin{array}{l}0.000 \\
(0.005)\end{array}$ & & $\begin{array}{c}0.018 * * \\
(0.009)\end{array}$ & $\begin{array}{c}0.019 * * \\
(0.009)\end{array}$ \\
\hline advocate_weight_g & $\begin{array}{l}-1.664 \\
(2.441)\end{array}$ & & $\begin{array}{c}-10.418^{* *} \\
(4.488)\end{array}$ & $\begin{array}{c}-11.492^{* * * *} \\
(4.366)\end{array}$ \\
\hline elite_weight & $\begin{array}{l}-1.876 \\
(2.492)\end{array}$ & & $\begin{array}{c}7.278 \\
(4.582)\end{array}$ & $\begin{array}{c}9.048 * * \\
(4.301)\end{array}$ \\
\hline general_weight & $\begin{array}{l}-0.789 \\
(2.397)\end{array}$ & & $\begin{array}{l}-4.829 \\
(4.407)\end{array}$ & \\
\hline peer_weight_g & $\begin{array}{l}1.198 \\
(2.351)\end{array}$ & & $\begin{array}{c}38.519 * * * \\
(4.322)\end{array}$ & $\begin{array}{c}38.642 * * * \\
(4.230)\end{array}$ \\
\hline percent_advocates & $\begin{array}{l}-2.619 \\
(2.346)\end{array}$ & & $\begin{array}{c}0.043 \\
(4.315)\end{array}$ & \\
\hline advocate_zeal & $\begin{array}{c}2.647 \\
(2.394)\end{array}$ & & $\begin{array}{c}11.148^{* *} \\
(4.401)\end{array}$ & $\begin{array}{c}11.209^{* *} \\
(4.313)\end{array}$ \\
\hline degrade_percent & $\begin{array}{c}0.022 \\
(0.024)\end{array}$ & & $\begin{array}{c}-0.686^{* * * *} \\
(0.045)\end{array}$ & $\begin{array}{c}-0.685 * * * \\
(0.043)\end{array}$ \\
\hline mu_activist_state & $\begin{array}{c}3.154 \\
(2.511)\end{array}$ & & $\begin{array}{l}-3.463 \\
(4.616)\end{array}$ & \\
\hline mu_activist_threshold & $\begin{array}{c}-14.103 * * * \\
(2.430)\end{array}$ & $\begin{array}{c}-14.636^{* * *} \\
(2.197)\end{array}$ & $\begin{array}{c}-20.338 * * * \\
(4.469)\end{array}$ & $\begin{array}{c}-18.660^{* * *} \\
(4.279)\end{array}$ \\
\hline Population & $\begin{array}{c}0.001 \\
(0.002)\end{array}$ & & $\begin{array}{c}0.015 * * * \\
(0.004)\end{array}$ & $\begin{array}{c}0.014 * * * \\
(0.004)\end{array}$ \\
\hline Constant & $\begin{array}{c}7.125 \\
(4.656)\end{array}$ & $\begin{array}{c}10.193 * * * \\
(1.269)\end{array}$ & $\begin{array}{c}23.944 * * * \\
(8.561)\end{array}$ & $\begin{array}{c}14.854 * * \\
(6.954)\end{array}$ \\
\hline $\begin{array}{l}\text { Observations } \\
\text { R-squared }\end{array}$ & $\begin{array}{c}100 \\
0.367\end{array}$ & $\begin{array}{c}100 \\
0.312\end{array}$ & $\begin{array}{c}100 \\
0.824\end{array}$ & $\begin{array}{c}100 \\
0.815\end{array}$ \\
\hline
\end{tabular}

Interestingly, norm adoption rates by the general population are not all dependent on the percentage of advocates in the simulation, but the weight they place on advocates' opinions has an inverse relationship on the outcome of norm adoption. This makes sense relative to the advocates' influence on elites as well in that advocates who are too zealous about their cause may in fact make those with whom they interact offput by humanitarianism and become even more difficult to persuade as the simulation moves on. The potential lesson for humanitarian advocates from this simulation is perhaps to be enthusiastic but not overly zealous about their cause in order to prevent backlash against the norm they are promoting. 


\section{CONCLUSIONS}

The most intriguing finding from this theoretical model that will shape future directions of research comes from the evaluation of the influence of the starting average opinion value for elite and general agents in the model (mu_activist_state). The number of elite and general norm adopters is relatively robust to starting conditions for opinion. In visually experimenting with the model, this is consistent with the observation that, regardless of starting values of parameters, most of the simulation runs stabilize after about 100 time steps. In fact, this is the reason we chose to cap the simulation runs at 200.

It appears that norms in the simulation get 'locked in' and eventually become immovable (Figure 1). In our model, this happens at about 200 time steps. Though the stabilization point for the number of norm adopters is different for different simulation runs, most simulation runs of the model look like those represented in Figure 1. What this means is that, while agents' opinions about the norm can continue to be changed throughout the simulation, the norm itself gets locked in at a certain degree of spread, rarely ever taking hold of the entire population, but rarely ever being entirely phased out.
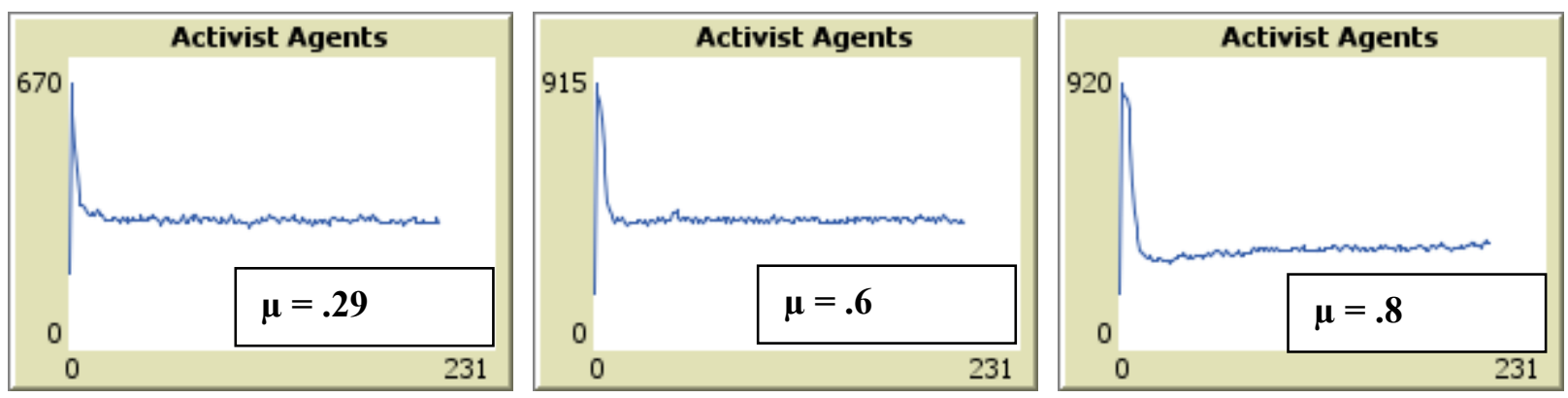

Figure 1: Simulation Stabilization Illustration.

This observation could hold for many other types of norms that also face no punishment mechanisms beyond peer pressure: political polarization; xenophobic sentiment; or gender bias. We have not yet fully explored the implications of social media networks, but this may only prove to amplify the situation as others have demonstrated in studies of echo-chambers related to political values and opinions (Boutyline and Willer 2017), particularly those that are driven by artificial mavens such as internet bots (Kumar, Villa, and Carley 2018). What makes this study unique is the lack of learning and strategy on the part of the agents. Unlike echo-chambers, the agents in our model are not seeking out others who are like them and clustering with like-minded individuals (virtually or spatially). In fact, the same echo-chamber phenomenon appears to occur without proximity, indicating that norm adoption may be even simpler than previously thought. Likewise, our model does not account for the potential social prestige of certain norm adoptions (Haaland and Wallevik 2014). We also have yet to insert competing norms that face challenges of adoption based on a new 'logic of appropriateness' (Finnemore and Sikkink 1998) that could suffer from incompatibility with a 'cultural match'(Checkel 1999). For instance, a community may have an underlying norm of xenophobia that competes with the norm of humanitarianism. Additionally, the model does not yet account for competition between elites for prestige and maximization of utility regarding norm adoption.

Though there are many features we could add to this model, the current model is grounded in political science norm diffusion theory and presents some interesting directions for future research. Most importantly, we intend to study, test, and evaluate the phenomenon of lock-in that we observe in the simulation data. If we can understand the underlying mechanisms of lock-in, perhaps this will lead to research on ways to dismantle lock-ins for the greater social good. Can we break norms of xenophobia in favor of humanitarianism? What role do civil society actors play in mitigating the relationship between norm promotion and diffusion and the important advocate and elite actors in a system? These questions we hope to continue to explore in future iterations of the study. 


\section{ACKNOWLEDGMENTS}

The development of this research was in part supported by funding from the Research Council of Norway (MODRN grant, \#250449). This research was also supported by the Turing High Performance Computing cluster at Old Dominion University.

\section{REFERENCES}

Axelrod, Robert. 1986. "An Evolutionary Approach to Norms." American Political Science Review 80 (4):1095-1111. doi: 10.1017/S0003055400185016.

Bahar, Dany. 2018. Venezuela's refugee crisis: Views from the border. In UpFront. The Brookings Institution: The Brookings Insittution.

Boutyline, Andrei, and Robb Willer. 2017. "The Social Structure of Political Echo Chambers: Variation in Ideological Homophily in Online Networks." Political Psychology 38 (3):551-569. doi: doi:10.1111/pops.12337.

Boyer, Pascal. 2002. "Religion Explained: The Human Instincts that Fashion Gods." Spirits and Ancestors, New York: Vintage.

Checkel, Jeffrey T. 1999. "Norms, institutions, and national identity in contemporary Europe." International Studies Quarterly 41 (1):83-114.

Conte, Rosaria, and Mario Paolucci. 2001. "Intelligent Social Learning." Journal of Artificial Societies and Social Simulation 4 (1). doi: http://jasss.soc.surrey.ac.uk/4/1/3.html.

Cosse, Eva. 2017. Death and Despair in Lesbos: Freezing Winter Conditions Turn Deadly for Refugees in Greece. Human Rights Watch.

Daniels, Joe Parkin. 2018. "Colombia aid groups under strain as Venezuela crisis spills over." devex: Inside Development. Accessed August 7, 2018. https://www.devex.com/news/colombia-aid-groups-understrain-as-venezuela-crisis-spills-over-92525.

Dignum, Frank, and V. Dignum. 2009. "Emergence and enforcement of social behavior " 18th World IMACS Congress and MODSIM09 International Congress on Modelling and Simulation, Cairns.

Elsenbroich, Corinna, and Nigel Gilbert. 2013. Modeling Norm: Springer.

Elster, Jon. 1989. "Social Norms and Economic Theory." The Journal of Economic Perspectives 3 (4): 99117.

Epstein, Joshua M. 2001. "Learning to Be Thoughtless: Social Norms and Individual Computation." Computational Economics 18 (1):9-24. doi: 10.1023/A:1013810410243.

Finnemore, Martha. 1996. "Norms, culture, and world politics: insights from sociology's institutionalism." International Organization 50 (2):325-347. doi: 10.1017/S0020818300028587.

Finnemore, Martha, and Kathryn Sikkink. 1998. "International Norm Dynamics and Political Change." International Organization 52 (4):887-917. doi: 10.1162/002081898550789.

Flentge, Felix, Daniel Polani, and Thomas Uthmann. 2001. "Modelling the emergence of possession norms using memes." Journal of Artificial Societies and Social Simulation 4 (4).

Flockhart, Trine. 2006. "Complex Socialization': A Framework for the Study of State Socialization." European Journal of International Relations 12 (1):89-118. doi: 10.1177/1354066106061331.

Flockhart, Trine. 2010. "Europeanization or EU - ization? The Transfer of European Norms across Time and Space." JCMS: Journal of Common Market Studies 48 (4):787-810. doi: 10.1111/j.14685965.2010.02074.x.

Gatherer, Derek. 2002. "Identifying cases of social contagion using memetic isolation: Comparison of the dynamics of a multisociety simulation with an ethnographic data set." Journal of Artificial Societies $\&$ Social Simulation 5 (4). 
Gilardi, Fabrizio. 2010. "Who Learns from What in Policy Diffusion Processes?" American Journal of Political Science 54 (3):650-666. doi: 10.1111/j.1540-5907.2010.00452.x.

Haaland, Hanne, and Hege Wallevik. 2014. "Accidental aid workers, aid-entrepreneurs, solidarity workers and the transnationals: A first typology of "home- made" aid initiatives in Norway and the Global South." 14th EADI General Conference "Responsible Development in a Polycentric World", Bonn.

Hurley, Susan L., and Nick Chater. 2005. Perspectives on Imitation: Mechanisms of imitation and imitation in animals: MIT Press.

Iglič, Hajdeja, and Andrej Rus. 2000. From Elite Reproduction to Elite Adaptation: The Dynamics of Change in Personal Networks of Slovenian Elites. Vol. 32.

Jager, Wander, and Frédéric Amblard. 2005. "Uniformity, Bipolarization and Pluriformity Captured as Generic Stylized Behavior with an Agent-Based Simulation Model of Attitude Change." Computational \& Mathematical Organization Theory 10 (4):295-303. doi: 10.1007/s10588-0056282-2.

Katzenstein, Peter J. 1996. The Culture of National Security: Norms and Identity in World Politics, New directions in world politics: Columbia University Press.

Klotz, Audie. 1995. "Norms reconstituting interests: global racial equality and U.S. sanctions against South Africa." International Organization 49 (3):451-478. doi: 10.1017/S0020818300033348.

Kumar, Sumeet, Ramon Alfonso Villa, and K. M. Carley. 2018. "Identifying Bots that Spread Fake News." SBP-BRiMS Washington, D.C.

Lebow, Richard N. 2008. A Cultural Theory of International Relations. Cambridge: Cambridge University Press.

Lehmann, David. 2005. "The Cognitive Approach to Understanding Religion." Review of In Gods We Trust: The Evolutionary Landscape of Religion, Samuel Atran; Religion Explained: The Human Instincts That Fashion Gods, Spirits and Ancestors, Pascal Boyer. Archives de sciences sociales des religions 50 (131/132):199-213.

Lopez, Fabiola Lopez y 2003. "Social Powers and Norms : Imapct on Agent Behaviour " PhD, Department of Electronics and Computer Science, University of Southampton

Lopez, Fabiola Lopez y, Michael Luck, and Mark d'Inverno. 2002. "Constraining autonomy through norms." The First International Joint Conference on Autonomous Agents and Multiagent Systems (AAMAS), New York.

March, James G., and Johan P. Olsen. 1998. "The Institutional Dynamics of International Political Orders." International Organization 52 (4):943-969. doi: 10.1162/002081898550699.

Miller, John H. 1998. "Active Nonlinear Tests (ANTs) of Complex Simulation Models." Management Science 44 (6).

Moskovko, Maria. 2012. "Diffusion of European Norms: Adoption of the principle of rule of law by Georgia and Ukraine." Masters, Department of Political Science, Lund University (2971194).

Powers, Rob A, and Yoav Shoham. 2004. "New Criteria and a New Algorithm for Learning in Multi-Agent Systems." NIPS.

Richerson, Peter J., and Robert Boyd. 2005. Not By Genes Alone: How culture transformed human evolution: The University of Chicago Press.

Salimi, Khadijeh, Erika Frydenlund, José J. Padilla, Hege Wallevik, and Hanne Haaland. 2018. "How does humanitarianism spread? Modeling the origins of citizen initiatives through norm diffusion." Winter Simulation Conference, Gothenburg, Sweden, December 12-14.

Savarimuthu, Bastin Tony Roy, Stephen Cranefield, Maryam A. Purvis, and Martin K. Purvis. 2010. "Oblication Norm Identification in Agent Societies." Journal of Artificial Societies and Social Simulation 13 (4). doi: 10.18564/jasss.1659. 
Sen, Sandip, and Stéphane Airiau. 2007. "Emergence of norms through social learning." Proceedings of the 20th international joint conference on Artifical intelligence, Hyderabad.

UNHCR. 2017. "Operational Portal Refugee Situations: Mediterranean Situation: Greece." [Data Portal], accessed December 18. https://data2.unhcr.org/en/situations/mediterranean/location/5179.

UNHCR. 2018. "Operational Portal of Refugee Situzations: Venezuela." UNHCR, accessed August 7. https://data2.unhcr.org/en/situations/vensit.

Villatoro, Daniel. 2010. "A Taxonomy of Social Norms." Artificial Intelligence Research Institute (IIIA), Barcelona.

Waltz, Kenneth N. 2010. Theory of international politics: Waveland Press.

Wendt, Alexander. 1999. Social Theory of International Politics. Cambridge Cambridge University Press.

Wolpert, David H., and Kagan Tumer. 2002. "Collective intelligence, data routing and braess' paradox." Journal of Artificial Intelligence Research 16 (1):359-387

Young, H. Peyton. 1996. "The Economics of Convention." Journal of Economic Perspectives 10 (2):105122. doi: doi: 10.1257/jep.10.2.105.

Young, H. Peyton. 2006. "The Diffusion of Innovations in Social Networks." In The Economy as an Evolving Complex System III: Current Perspectives and Future Directions, edited by Lawrence E. Blume and Steven N. Furlauf. Oxford, UK: Oxford University Press.

Young, H. Peyton 1993. "The Evolution of Conventions." Econometrica 61 (1):57-84. doi: $10.2307 / 2951778$.

\section{AUTHOR BIOGRAPHIES}

KHADIJEH SALIMI is a doctoral candidate in International Relations at Old Dominion University, with an emphasis in M\&S approaches to political issues. Her dissertation focuses on norm diffusion, especially norms of social equity. Her email is ksali001@odu.edu.

ERIKA FRYDENLUND is Research Assistant Professor at VMASC at Old Dominion University. Her research focuses on social justice and mobility, specifically refugees and other forced migrants. Her dissertation included fieldwork among refugees in protracted situations in western Rwanda along the border of the Democratic Republic of Congo. Her email is efrydenl@odu.edu.

JOSE J. PADILLA is Research Assistant Professor at VMASC at Old Dominion University. His research focuses on the understanding and modeling of problem situations. Ongoing research focuses on methodological development for M\&S of human behavior using social media data and agents; simulating users, insider threats and hackers for cybersecurity; and designing and developing platforms for simulation development and data capture. His email address is jpadilla@odu.edu.

HANNE HAALAND is Associate Professor and Head of the Department of Global Development and Planning at Agder University. Her main research focus is on Citizen Initiatives (CI), both in a development context and in the context of the European refugee crisis. Together with Wallevik she has conducted research on integration of refugees into Norwegian society, focusing on the role of paid and voluntary work as factors in successful integration. Her email address is hanne.haaland@uia.no.

HEGE WALLEVIK is Associate Professor at the Department for Global Development and Planning at the University of Agder, Norway. Her research focuses on new development actors, specifically Citizen Initiatives for Global Solidarity, in disparate humanitarian environments. Her long-term fieldwork for her $\mathrm{PhD}$ was done in Tanzania (Zanzibar) where she focused on women and economic activities. Lately she has also done fieldwork on this thematic in Greece, Lesvos. Her e-mail is hege.wallevik@uia.no. 